\title{
The Effect of Climate Change and Variability on the Livelihoods of Local Communities: In the Case of Central Rift Valley Region of Ethiopia
}

\author{
Mikias Biazen \\ Wondo Genet College of Forestry and Natural Resources, Hawassa University, Shashemene, Ethiopia \\ Email: atsed.wallia@gmail.com
}

Received 13 April 2014; revised 25 May 2014; accepted 15 July 2014

Copyright (C) 2014 by author and OALib.

This work is licensed under the Creative Commons Attribution International License (CC BY). http://creativecommons.org/licenses/by/4.0/ CC) (i) Open Access

\begin{abstract}
A study was conducted with the objectives of investigating the effect of climate change and variability on the livelihood of the local community in Arsi Negele District, Central Refit Valley Region of Ethiopia using group discussions, structured questionnaire and personal observations. The trends of climate change and variability in the study area showed gradual change. Erratic rainfall, frequent rain delay, heavy and un-seasonal rainfall, drought, and seasonal variations are indicators of climate change. The pattern of temperature, rainfall, and high wind caused the reduction of agricultural production and productivity, shortage of water, drying of shrubs and other vegetations, which affect the livelihood of the community. The problem is more sensitive for the women, poor, children, large sized family, and landless farmers. Thus, the vulnerability of climate change is more accelerated by massive expansion of agricultural land, the increment of landlessness families and huge water shortage in the study area. Moreover this study advocating climate change and variability has accelerated the degradation of natural environment and strongly affects the community's life style over time. Though, as stated above this study was conducted using some and simple research variables to demonstrate the problem. But, it is used as an initial thought for further and detailed investigations about the issue. Therefore, stakeholders required to take in hand these challenges both from short and long-term policy perspective to reduce susceptibility of next generation.
\end{abstract}

\section{Keywords}

Climate Change, Variability, Vulnerability, Livelihood, Impact, Community

Subject Areas: Environmental Sciences

How to cite this paper: Biazen, M. (2014) The Effect of Climate Change and Variability on the Livelihoods of Local Communities: In the Case of Central Rift Valley Region of Ethiopia. Open Access Library Journal, 1: e453. 


\section{Introduction}

Climate change is rapidly emerging as one of the most serious threats that humanity may ever face. Hence, it has recently become a pressing issue in various development, environment, and political forums at the national, regional, and international levels [1] and [2]. According to [3], poor households are not only located in high-risk areas, but suffer lack of economic and social resources. Different investigation revealed that variability and change of climate are major threats for developing countries [4]. Most of the time the challenge is being magnified by global climate change [5].

According to [6], the severity of climate variability and change profoundly influence social and natural environments throughout the world. Hence, with the consequent impacts on natural resources and industry that can be large and far-reaching [7]. In addition to that, climate change strongly influences forest productivity, species composition, and the frequency and magnitude of disturbances that impact forests [8].

Many researchers confirmed that, in Ethiopia, climate change poses particular risks to poor farmers and pastoralists who have an immediate daily dependence on climate sensitive livelihoods and natural resources.

This research was carried out in the Central Refit Valley Region of Ethiopia the low land part of Arsi Negele districts. The area is known by agricultural potential, which is reflected in the diversity of crops and animal resources. But, drought, shortage of water, decreasing of agricultural productivities, and degradation of natural resources are the main challenges in the day-to-day activity of local farmer's in the study area.

According to the socio-economic activity and geo-ecological location criteria by [9] and [10], the study area is categorized as a hotspot for climate change impacts and is affected by drought repeatedly. The main objective of this research is to investigate the effect of climate change and variability on the livelihood of the local community in the study area.

The data were collected from both primary and secondary data sources and purposive sampling techniques were used to generate the desired outputs.

\section{Material and Methods}

\subsection{Description of the Study Area}

The study was conducted in the lowland area of "Arsi-Negele" district which is located on $7^{\circ} 09^{\prime}-7^{\circ} 41^{\prime} \mathrm{N}$ and $38^{\circ} 25^{\prime}-38^{\circ} 54^{\prime} \mathrm{E}$, and $210 \mathrm{~km}$ south of Addis Ababa along the road to "Shashemene-Hawassa". The district is part of Ethiopian Central Rift Valley, covering an area of $600 \mathrm{~km}^{2}$. About $80 \%$ of the population is rural [11].

The National Meteorological Services Agency [12] data, Langano station, shows an annual mean rainfall of less than $700 \mathrm{~mm}$ (ranges between 264 and $968 \mathrm{~mm}$ ), whereas the mean annual minimum and maximum temperatures are $13.5^{\circ} \mathrm{C}$ and $27.7^{\circ} \mathrm{C}$, respectively. The most common coping strategy of the farmers during crop failures has been the burning and selling of charcoal. As a result the once densely wooded area has been almost completely deforested [13]. The vegetation converge of the area can be classified mainly as acacia woodland with some thorny shrub lands occurring around the lakes, open acacia woodland dominates one in the lowland part of the district. The characteristics of species are woody plants including various types of acacia trees, shrub, sub-shrub with different distribution and abundance [14]. The area characterized by crop-livestock based farming systems. The overall farming system is strongly oriented towards grain production dependent on the use of oxen for land preparation [15].

\subsection{Methods of Data Collection}

\section{Primary Data Collection}

In order to achieve the stated objective the study used both primary and secondary sources of data. The primary data sources were generated by the researcher in order to measure the independent variables. Data were collected through group discussions, structured questionnaire, key informant interviews, field observation and intensive ground field surveys were conducted.

Key informant Interview: in addition to the group discussion, interview were carried out with individuals who have lived long time in the study area and had detail information about the past and present situations of the area. The informants selected were elder peoples, 3 PA leaders, and 8 development agent. Purposive sampling was used to select the key informants to get the general information about the study area. Because, purposive type of data collection is a rational methodology, it helps to clearly explore target groups to generate the desired output in the study area. 
Household Survey Data: This survey focused on information about demographic characteristics of the households, household asset (land, land size), and individual level land use system, perceptions towards the trends of climate change and variability in the study area.

\subsection{Secondary Data Collection}

Different secondary sources of data were used to derive the required information for this study. Data like; recorded population and climate data were collected from Ethiopia Metrology Agency and peasant associations. Secondary data sources, review of relevant published and unpublished documents and processing of recorded metrological data on the study area. Besides, the administrative boundary of the study area was obtained from Bureau of Water Resources in Oromia region. The collected household data were summarized and analyzed using Statistical Package for the Social Sciences [16].

\section{Result and Discussion}

\subsection{Trends of Climate Change and Variability}

The trend of climate change and variability in the study area were gradually changed.

The rainfall is highly variable both in amount and distribution across regions and seasons [17] and [18]. The study area has experienced frequent climatic shocks, extended drought and delay in the onset of rain, erratic and low precipitation, and heavy and un-seasonal rainfalls these are some of the indicators of climate change and variability. As shown in (Figure 1 and Figure 2) the intensity, duration, frequency and distribution of rainfall decreased time to time, whereas the temperature is increasing at an alarming rate. According to Negele Metrology Station recorded data (1981-2010), the precipitation trend of the area has shown dramatic decline, and the annual average temperature has shown an alarming rate of increase from (1981-2009).

\subsection{Rainfall Variability and Its Trends}

The baseline recorded climate data that was developed using historical data of temperature and precipitation from 1981-2009 for Negele stations in Arsi Negele district showed the year-to-year variation of rainfall for the period between 1981 to 2009 over the district expressed in terms of normal rainfall averaged for district.

Trend analysis of annual rainfall in Ethiopia shows that rainfall remained more or less constant when averaged over the whole country while a declining trend has been observed over the Northern and Southwestern Ethiopia [2].

As can be seen from Figure 1 the district has experienced both dry and wet years over the last 20 and above years 1981 to 2009. This means that, years 1987, 1988, 1989, 1991, 1992 and 2002 were dry and the amount, distribution, duration and intensity of rainfall decreased, while 1981, 1982, 1990, 1999, 2002, 2003, 2004, 2005 were wet and somehow the trends of rain fall was regular.

However, starting from 2006-2009 the amount of precipitation has decreased, uneven and also un-seasonal; as a result, it can cause drought, shortage of water and drying of vegetations in the study area.

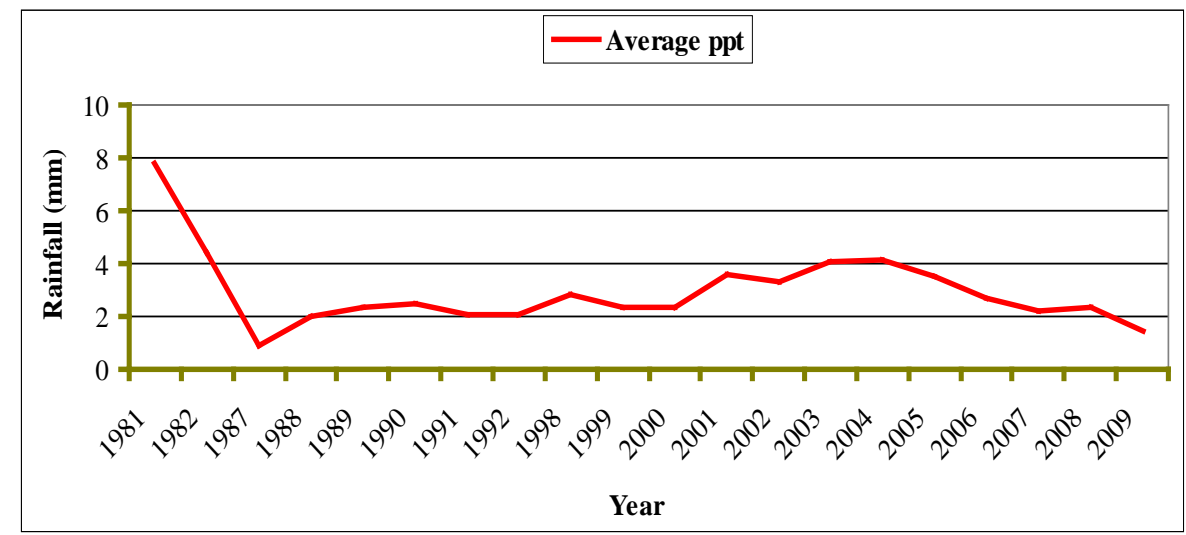

Figure 1. Year to year, variability of annual rainfall and trend over the district expressed in mean annual rain fall (data source NMA, 2010). 


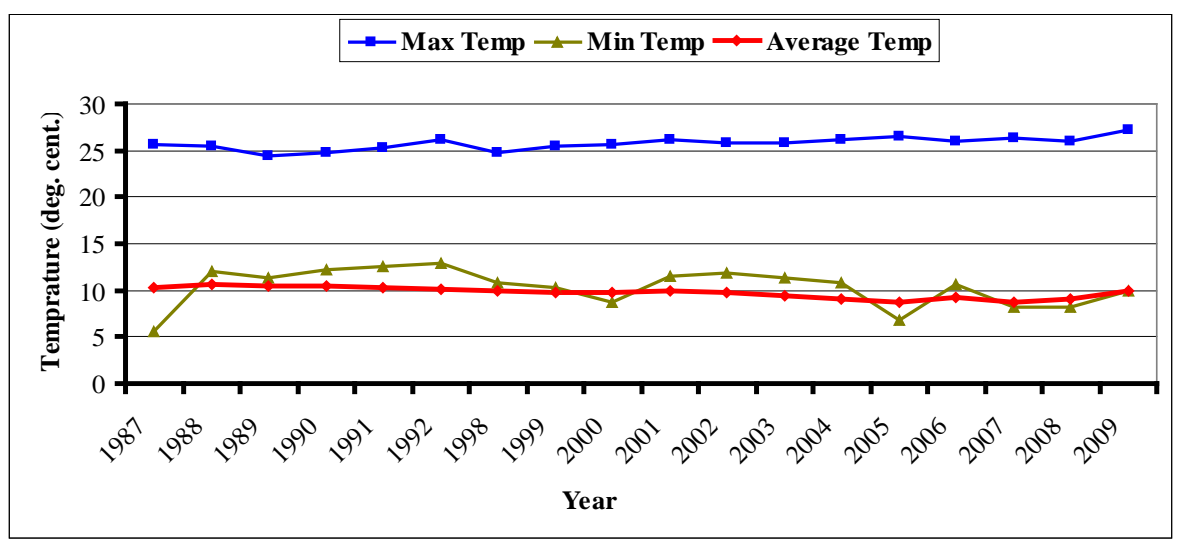

Figure 2. Year-to-year, variability of annual minimum, and maximum temperature over the district expressed in temperature difference (data source NMA, 2010).

The majority of the respondents perceived that the current prolonged drought is the result of shortage in rainfall as the most notorious climate shock in their lifetime in the study area.

\subsection{Temperature Variability and Its Trend}

Earliest climatological station data has shown an irregularity of $-4^{\circ} \mathrm{C}$ while the result is unexpectedly increased to $4^{\circ} \mathrm{C}$ in the preceding years since 2006 [21]. As illustrated from the Figure 2, the year-to-year variation of annual minimum and maximum temperature within the district for the period 1981 to 2009 expressed in terms of temperature differences from the averaged data of the stations (Figure 2).

The result showed that, the year 1992, 2001, 2004, 2005 and 2009 were the warmer while, the year 1987, 2000, 2005, 2007 and 2008 are the most cool years which is experienced over the last 20 and above years. However, the recent years $(2007,2008$ and 2009) are the warmest compared to the early years $(1987,1988$, 1999, 2000 and 2005).

Moreover, the result clearly revealed that there has been a warming trend in the annual maximum and minimum temperature over the past 20 years. On the other hand, over $65 \%$ of the respondents perceived that the current prolonged drought is the most recognized climate shock in their lifetime in the study area. However, the respondents were cultivating drought resistance crops and trees to sustain their life. From their experience the interviewed key informants reopened that, there is an overall increasing temperature and downward trend of precipitation in the area (Figure 1 and Figure 2) and can cause for different socio-economic problems. Figure 3 illustrates the yearly temperature variability in the study area.

Based on Figure 3 the maximum temperature variability were recorded at 1992 (26.2), 2001 (26.0), 2004 (26.1), 2005 (26.4), 2007 (26.3) and 2009 (27.1). Whereas, the initial 1987 (5.5), 2000 (8.71), 2005 (6.82), 2007 (8.11) and 2008 (8.15) were recorded as minimum yearly temperature value in the study area. However, during the time period of 1988, 1989, 1990, 1991, 1992, 1998, 1999, 2000, 2001, 2002 and 2009 the average temperature of the study site shows similar recorded value while the rest year depicted a up and down or inconsistency recorded value. On the other hand, the interview result has also confirmed the occurrence above mentioned temperature variability in the study area. The fluctuation of rainfall and temperature condition can cause for the shortage of potable water, loss of soil fertility, reduction of agricultural production and productivity, whereas, soil erosion and land degradation has also increased. Hence, according to respondents report, the challenges are severe and more frequent in the lowland area of the district. Interviewed women's in the study area were pointed out that because of climate change the water resources also depleted time to time and face a big water shortage problems, as much of their time is spend fetching water from distance, this is very difficult in the dry season.

Above $85 \%$ of the respondent reported that, a change in weather conditions particularly, the pattern of temperature, and rainfall, and strong wind erosion on their fields can cause the reduction of agricultural production and affect the livelihood of the community.

Population growth and the expansion of cultivated land mentioned as the underlying factors that influenced the exploitation of the acacia-based grasslands. Due to lack of resources and food in time of drought, poor farmers 


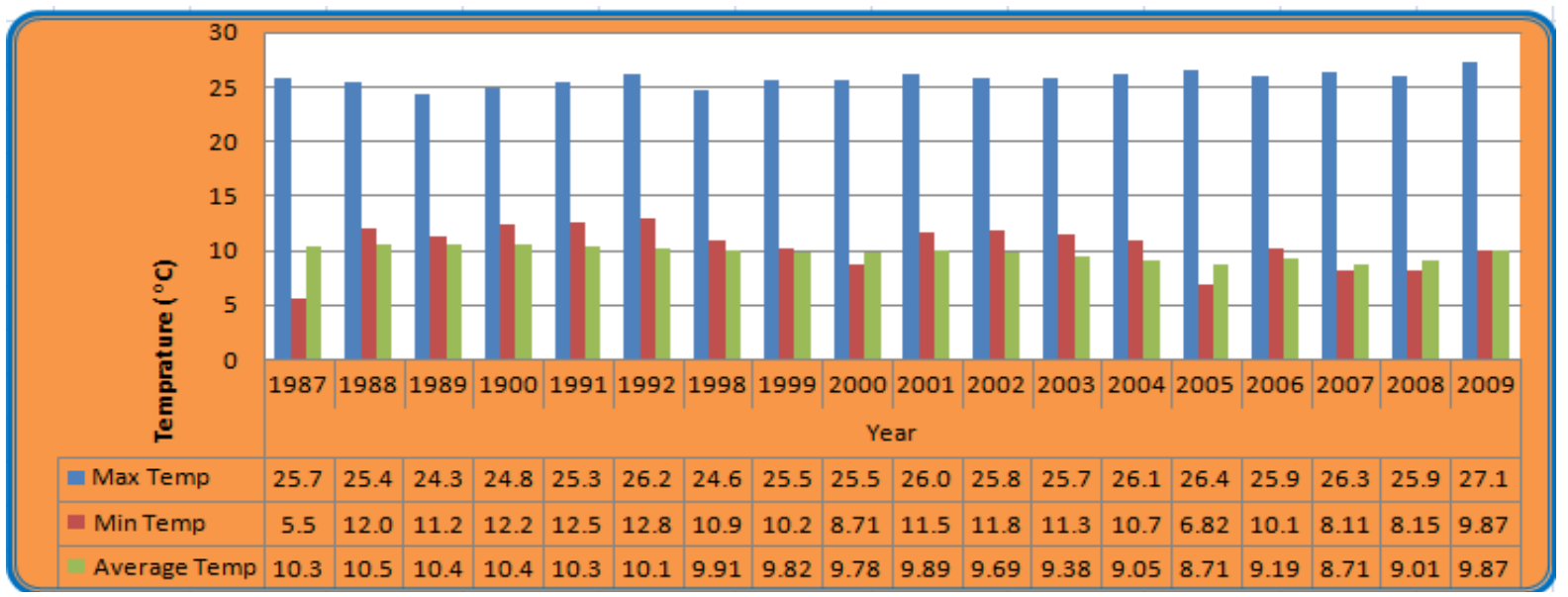

Figure 3. Annual Temperature Variability (maximum, minimum and average) of the study area.

depend on the sale of firewood and charcoal as a source of income.

As a result, the acacia woodland and other vegetations decreased. However, farmers are aware that charcoal production is an illegal activity and therefore do not talk openly about it elsewhere. Mostly youths are involved in such activity because in the area most of youths are jobless or unemployment.

\subsection{Communities Perception on Climate Change and Variability}

According to the National Meteorological Agency, long-term climate change in Ethiopia is associated with changes in precipitation patterns, rainfall variability, and temperature, which could increase the country's frequency of both droughts and floods [19].

As shown in Table $182 \%$ of the respondents revealed that the dry season have become longer, and main wet seasons fail more often. The starting and ending of the rainy season is also becoming more unpredictable, as they may come early or late.

The rains may stop very early and be more erosive because there is less vegetation cover in the area. The Table 1 illustrates the overall perception of the community about the trends of climate change and variability in terms of rainfall, temperature, drought, rate of floods in the study area.

\subsection{Indicators of Climate Changes}

The majority of the farmers perceived that rainfall and temperature variability is the most important indicators of climate change and variability. Their agricultural practices depend on four months of the "Kiremit" season for their annual production. Almost $75 \%$ of the interviewees were responding that there is a big difference between the past and the present climatic conditions.

As the farmers said seasonal variation, occurrence of unusual long rainy and dry season, erratic rainfall, occurrence of abnormal hot and cold temperature, impact of abnormally hot/cold temperature on normal life, occurrence of certain diseases attributed to climate change, denudation of forest resources, followed by land degradation, and deforestation.

On the other hand, occurrence of acute shortage of both surface and underground water resources during the prolonged dry seasons, excess overflows of water bodies during the prolonged rainy seasons and excessive heat during daytime and excessive cold weather during nighttime are some of the major indicators of climate change and variability in the study area.

\subsection{Social Consequences of Climate Change}

\subsubsection{Changing of LU/Land Cover}

Climate change has impact on Ethiopian agriculture. Erratic rainfall and increasing amount of temperature are influencing the agricultural system of the country. Many regions have been severely affected by climate changes in northern Ethiopia [20]. 
Table 1. Communities perception on climate change and variability in the study area.

\begin{tabular}{|c|c|c|}
\hline Indicators & Trends & Attribute of the change or variability \\
\hline $\begin{array}{l}\text { Temperature } \\
\text {-hot and dry months }\end{array}$ & $* *+$ & Failure of short and main wet seasons \\
\hline Rainfall amount & $-* *$ & Comes early or late and stops early \\
\hline Rainfall intensity & ${ }^{* *+} \Gamma^{* *}$ & Sometimes in short period, heavy rainfall with high rate of runoff \\
\hline Rainfall duration & $-^{* *}$ & During wet season, it rains for very few days or hours \\
\hline Rainfall distribution & $-* *$ & $\begin{array}{l}\text { Often, both wet seasons become part of the dry season; the main wet season is } \\
\text { more reliable than the short one }\end{array}$ \\
\hline $\begin{array}{l}\text { Frequency of } \\
\text {-drought } \\
\text {-famine } \\
\text {-flooding }\end{array}$ & $\begin{array}{l}* *_{+} \\
* *+ \\
* *+\end{array}$ & $\begin{array}{l}\text { Usually with failure of main and short wet season, } \\
\text { drought and famine are intensified, while flooding is due mainly to land-use } \\
\text { change, soil erosion and siltation of the river courses }\end{array}$ \\
\hline Duration of flooding & $* *+$ & $\begin{array}{l}\text { Mainly due to high rate of land degradation and runoff from upstream while the } \\
\text { water course is too shallow ton hold more water }\end{array}$ \\
\hline
\end{tabular}

The higher temperatures, increased drought, and decline the amount of rainfall that cause decrease in the cover of vegetation that protects the ground surface, increase soil erosion and land degradation.

Climate variability and change can contribute to land degradation by making current land use practices unsustainable and induce more rapid conversion of land to unsustainable uses. The combined effects of rising temperatures and reduction of rainfall in the study area can cause for the drying and reduction of forest and other vegetative resources.

\subsubsection{Drought}

Drought is one of the main problems in the study area, it has become severe and frequent in recent years, as compared to past decades, and the drought is repeated almost every year. Drought is the single most important climate related natural hazard affecting the country from time to time and it occurs anywhere in the world but its damage is not as severe as in Africa in general and in Ethiopia, due to low adaptive capacity [21].

The temperature increased, while rainfall decreased, therefore, no time to recover from its impacts overtime. Particularly, the last five and six years have seen more frequent and prolonged droughts. Throughout the drought period, the rains were not only insufficient but also extremely delay, erratic, unseasonal, and unpredictable.

\subsubsection{Crop Cultivation and Livestock Rearing}

Rising temperatures will cause shifts in crop growing seasons, which affects food security and changes in the distribution of disease vectors putting more people at risk from diseases such as malaria and dengue fever [22]. The majority of respondents reported that there is a critical problem during prolonged drought and during delay in the onset of rain land becomes dry and difficult to plough, forage deficit leads to weakness and oxen mortality, and lack of precipitation delay seed cultivation. It can cause failure of agricultural crops adversely affecting farmers who, totally depend on one season production system, which is rain fed agriculture.

Drought and delay in the onset of rain led to poor grass regeneration/forage deficit, water shortage, and heat stress on livestock, and consequently increased the mortality of the livestock, vulnerability to diseases and physical deterioration due to long distance travel for water.

\subsection{Impacts on the Local Community}

Climate change can influence humans directly, through impacts on health and the risk of extreme events on lives, livelihoods and human settlements, and indirectly, through influences of food security and the viability of natural resource-based economic activity [23].

All the interviewees confirmed that repeated climatic impacts occurred on the society in lowland area rather 
than highland area and it can cause for food deficits, educational dropouts, increased unemployment, increased susceptibility to diseases and failure to fulfill financial requirements, and lack of agricultural input and decreased soil fertility in the area.

Climate variations tend to disproportionately affect livelihoods of the rural poor as a result of their reduced capacity to buffer against climate risk through assets or the financial market [24]. Some of the interviews indicated that our life is depending on Meher rainfall crops like corn, maize, teff, wheat and barley, these are our staple food crops and also sometimes sold to fulfill other financial necessities, but the frequent delay of rain fall and seasonal variation can cause for the failure of Meher crop harvesting. The farming community was identified as the most vulnerable because of its dependence on agricultural production for its livelihood [19].

In fact, climate change affects all of the society members living in every agro climate zone. However, comparing farmers in the highland and lowlands, those living in the lowlands were more affected than those living in the highlands.

Changes in temperature and rainfall have had many negative impacts on human and animal health. For instance, serious disease outbreaks including cholera, meningitis, and malaria occurred due to the extreme fluctuation and alteration of temperature patterns and rainfall regimes in the study area.

\subsection{Who Is More Vulnerable to Climate Change Impact?}

Climate variability and change over the past century have already had measurable effects on ecosystems, societies, economies, and health [25]. Vulnerability is a function of geographic location, production system, social identity, and income, which is partly driven by processes of land reallocation, uncertainty of climate, lack of access to inputs to the productive process, processing, marketing, and declining or fluctuating market prices [26]. The vulnerability of Ethiopia to climate change impact is a function of several biophysical and socioeconomic factors [16].

Table 2 illustrates the effect of climate change and variability at various social groups in the study area. As indicated on Table 2, on average 78.2\%, 76.0\%, 46.7\% and 67.3\% respondents suggested children, women and large sized families and poor respectively are the most vulnerable to climatic shocks. In addition to that, Table 2 illustrates about $36.2 \%$ respondents suggested all farmer households are disproportionately affected and are equally vulnerable.

On the other hand, Table 2 depicted, the average respondents who were suggested that youth, elderly people, and men are most vulnerable to climatic impacts which accounts for $23.6 \%, 54.5 \%$, and $14.5 \%$ respectively. The interview with Negele district officials and experts suggested that poor, women, children, and old peoples are the most vulnerable compared to other groups. Conversely, the district officials includes all farmers and community members including large family size, livestock tenders, children, women and poor, all production systems mostly affected by the events.

According to [29], conditions in many slum areas are terrible: inadequate shelter combined with poor sanitation; extreme overcrowding and a high proportion of vulnerable women, children, youth, elderly and poor, with very low incomes and high unemployment. This is the result of extreme or high risk of disease and an extreme poverty trap for many urban residents.

\subsubsection{Vulnerability by Poor and Young Farmer}

In Ethiopia, climate change poses particular risks to poor farmers and pastoralists who have an immediate daily dependence on climate sensitive livelihoods and natural resources [9]. People paid the highest price because they lived in the areas most at risk from climate change, and among the poor, children suffered the most, paying with their health, their development and often with their lives.

Table 2 shows that, $67.3 \%$ and $23.6 \%$ of the respondent were reported that poor and young farmers are directly or/and indirectly affected by climate change respectively, but, even though, medium class farmers are affected, they response to the climatic change impact by selling the available assets (oxen, caw, donkey....etc), taking credits and leasing part of their lands for rich farmers.

According to [30], each year more than 3 million children under the age of five died from environmentally linked diseases, including diarrheal ailments linked to water accessibility, respiratory illnesses and malaria, which thrived on heat and humidity to kill a million people each year. Normally the livelihoods of poor farmers depend on daily labor and have low income and fewer reserves to absorb climate change impact. 
Table 2. Percentage of respondents on the most vulnerable social groups.

\begin{tabular}{|c|c|c|c|c|c|c|c|c|c|c|c|}
\hline \multirow{3}{*}{ PA } & \multicolumn{11}{|c|}{ Vulnerable Group in \% } \\
\hline & \multicolumn{2}{|c|}{ Gender } & \multicolumn{4}{|c|}{ Age and family size } & \multicolumn{3}{|c|}{ Wealth status } & \multicolumn{2}{|c|}{ Production system } \\
\hline & Men & Women & Children & Youth & Elders & $\begin{array}{c}\text { Family } \\
\text { Size }\end{array}$ & Poor & Medium & Rich & Livestock & $\begin{array}{c}\text { All } \\
\text { Group }\end{array}$ \\
\hline Galina Kello & 6.5 & 42.4 & 39.6 & 9.3 & 22.6 & 25.0 & 30.5 & 8.1 & 5.9 & 27.6 & 16.4 \\
\hline Hada Boso & 8.0 & 35.8 & 38.6 & 14.3 & 31.9 & 21.7 & 36.8 & 6.4 & 5.0 & 38.2 & 19.8 \\
\hline Average (\%) & 14.5 & 76.0 & 78.2 & 23.6 & 54.5 & 46.7 & 67.3 & 14.5 & 10.9 & 65.8 & 36.2 \\
\hline
\end{tabular}

Therefore, gradually they may also move the medium class farmers to the poor farmer level of wealth status. Rich farmers using the events as an opportunity, the better-offs also rent land from other affected groups (poor, in some extent medium class farmers) at cheaper price.

In addition, youths are more vulnerable as compared to old because the former have enough land resources than latter the difference in landholding and absence of employment opportunities in the districts. Though old have inherited the land for their offspring, they are generally better in landholding and have better immunity to cope with climatic shocks, whereas youth are generally poor because of unemployment and landlessness.

\subsubsection{Vulnerability by Pastoralist}

As indicated on Table 2, 65.8\% of the interviewers responded that livestock's were highly affected by the existing prolonged drought, due to the depletion of acacia based grass land and drying out of water resources and animals are weak, deteriorate their body and die, they are forced to sell the livestock. According to the PAs official like; Kedir, Mamo and other interviewed key in formants said that, households with less number of livestock were better at coping with the impact due to their better fodder finding and management, less cost to buy feed and less effort to store or prepare fodder at home every time. However, households with large livestock number could not handle the feeding and lacked other income sources or savings as the livestock body deteriorates and livestock market price continue to fall, and it can cause for economic crisis due to climate change (drought).

\subsubsection{Vulnerability by Gender}

Women and girls in particular were disproportionately affected by climate variability. During the time of drought and food insecurity women tends to stay home with their children, while men move away to look for alternative means of survival.

Women also have fewer options to find other ways of making a living, especially since women's literacy rate is not even half of that of men. Women also not given a say in household decisions and are frequently without cash savings or assets to sell to buy food and other basic items.

Table 2 confirmed that about $76.0 \%$ of the respondents were suggested that women's are more vulnerable to climate change as compared to $14.5 \%$ respondent for men. As the respondents report, the district particularly Gallina Kello PA traditionally women's are the prime responsible for each off-farm and non-farm activities income sources, take credit and return it timely. According to PA managers' report, women represent only $18 \%$ and $21 \%$ of the total landholders respectively in both Galina Kello and Hada Boso PA's.

The percentage of women students attending in the surrounding school grade level, satellite school, primary school, and secondary school in 2009/010 was $13 \%, 40 \%$, and $21 \%$ respectively. This literacy indicator shows a declining trend of women at higher school levels and at higher ranks, representing poor school attendance and low achievement and/or high dropouts from school.

\subsubsection{Vulnerability by Family Size}

Polygamy is a common practice and household size is among the wealth classification criteria. For instance, in Negele district household size 10 and above is one of the criteria considered to classify as better-off [17].

However, the tradition is go wrong with rising land scarcity, unemployment, high dependency ratio and increased climatic unpredictability. As indicated on Table 2, 46.7\% of the respondents were report that, family size has its own impact to tackle the occurrence climatic shocks and other uncertainties. The farmers stated that the demographic composition of each household members are young, which are economically inactive and sus- 
ceptible to malnutrition and other diseases; thus, the situation is more desperate as few household members cannot afford to manage the requirement of the family including sending children to school.

\section{Conclusions}

This investigation illustrated the increasing trend of climate change and its impact on livelihood of the local communities, besides that, the variability of climate change is accelerating the vulnerability of various socio-economic activities of the community. The gradual alteration of the environment can cause surface and ground water shortage in the area and is more likely to continue to constrain for other livelihood activities.

Frequent rain delay, erratic precipitation, drought, seasonal variation, heavy and unseasonal rainfalls occurrence of unusual long rainy and dry season, occurrence of abnormal hot and cold temperature are also severe concerns for all the communities and some of the indicators of climate change and variability in the study area.

This result can cause the occurrence of serious animal and human disease outbreaks like, cholera, meningitis, and malaria. The study reveals that on average $78.2 \%, 76.0 \%, 46.7 \%$ and $67.3 \%$ respondents suggested children, women and large sized families and poor respectively are the most vulnerable to climatic shocks.

Climate change has also a great impact on crop cultivation and livestock rearing: delay in the onset of rain makes the land become dry and difficult to plough, forage deficit leads to weakness and oxen mortality (engine of subsistent cultivation), and lack of precipitation delays germination of cultivated seeds. In general, climate change and variability have negative impact on the livelihoods of the community. Local and participatory adaptive metrologies are the most important to tackle the existing problems.

\section{Recommendation}

Based on this initial study finding the following points were recommended for further investigation:

- The vulnerability of lowland communities are a serious concern in the future, thus interventions will required to address this hot issue.

- $\quad$ Preparing long-term adaptation plans, based on the sharing of best practices through the participation of communities, academicians, and research institutions.

- Ensuring community participation especially women's and youths, in both formulating climate change policies, environmental and drought monitoring systems and improve their disaster risk reduction capacity.

- Promote different development programs and addressing vulnerable groups through development of better alternative mechanisms.

\section{Acknowledgements}

This research was funded by Volkswagen foundation local project, Wondogent, Ethiopia. I thank the farmers who participated in this research as a whole. I wish also to thank reviewers for their comments on the manuscript.

\section{References}

[1] IPCC (2001) Climate Change 2001: Impacts, Adaptation, and Vulnerability: Contribution of Working Group II to the Third Assessment Report of the Intergovernmental Panel on Climate Change. Cambridge University Press, Cambridge.

[2] IPCC (2007) Climate Change Impacts, Adaptation and Vulnerability: The Working Group II Contribution to the IPCC Fourth Assessment Report. http://www.ipcc-wg2.org/

[3] Orinda, V.A. and Murray, L. (2005) Adapting to Climate Change in East Africa: A Strategic Approach. Gatekeepers Series 117, International Institute for Environment and Development, London.

[4] Cline, W. (2007) Global Warming and Agriculture: Impact Estimates by Country. Peterson Institute, Washington DC.

[5] Lobell, D.B., Burke, M.B., Tebaldi, C., Mastrandrea, M.D., Falcon, W.P. and Naylor, R.L. (2008) Prioritizing Climate Change Adaptation Needs for Food Security in 2030. Science, 319, 607-610. http://dx.doi.org/10.1126/science.1152339

[6] Schubert, S., Dole, R., van den Dool, H., Suarez, M. and Waliser, D. (2002) Prospects for Improving Forecasts of Weather and Short-Term Climate Variability on Subseasonal (2-Week to 2-Month) Time Scales. NASA Technical Report Series on Global Modeling and Data Assimilation, NASA/TM-2002-104606, 23, 171p.

[7] Terra Africa (2009) Land \& Climate, the Role of Sustainable Land Management (SLM) for Climate Change Adapta- 
tion and Mitigation in Sub-Saharan Africa (SSA). Issue Paper, 3p.

[8] USCCSP (1994) The Effects of Climate Change on Land Resources in the United States, USGS, 2007. Climate Variability and Change. http://pubs.er.usgs.gov/usgspubs/cir/cir1309

[9] Alebachew, A. and Aklilu, A. (2009) Climate change in the Southern Lowlands of Ethiopia: Local Level Evidences, Impacts and Adaptation Responses. Forum for Social Studies, cop., Addis Ababa.

[10] Thornton, P.K., et al. (2006) Mapping Climate Vulnerability and Poverty in Africa. Report to the Department for International Development, The International Livestock Research Institute (ILRI), Nairobi.

[11] Morton, J.F. (2007) The Impact of Climate Change on Smallholder and Subsistence Agriculture. Proceedings of the National Academy of Sciences, 104, 19680-19685. http://dx.doi.org/10.1073/pnas.0701855104

[12] CSA (2006) National Population Statistics. Addis Ababa: Federal Democratic Republic of Ethiopia, Central Statistical Authority.

[13] National Meteorological Services Agency (NMSA) (2010) Ten-Day Agro-meteorological Bulletin, Date of Issue Feb, 15 2010, Adama Branch Office, Ethiopia.

[14] Garedew, E., Sandewall, M., Söderberg, U. and Campbell, B. (2009) Land-Use and Land-Cover Dynamics in the Central Rift Valley of Ethiopia. Environmental Management, 44, 683-694. http://dx.doi.org/10.1007/s00267-009-9355-Z

[15] Abate, F. (2009) Climate Change Impact on Livelihood, Vulnerability and Coping Mechanisms: A Case Study of West-Arsi Zone, Ethiopia. MSc. Thesis, Lund University, Lund.

[16] ORS (2004) Oromia Regional State government: Socio Economic Profile of East Shoa Zone.

[17] Ribot 1995. Statistical Procedure for Social Science (SPSS) (2003) Statistical Procedures for Social Sciences (SPSS), Version 13. INC, Chicago.

[18] Kifilu, T. (2003) Field Comparison of Resource Utilization and Productivity of Three Grain Legumes under Water Stress. Ph.D. Thesis in Agrometeorology, Department of Soil, Crop and Climate Sciences, University of the Free State, Bloemfontein.

[19] Admassie, A., Adenew, B. and Tadege, A. (2006) Perceptions of Stakeholders on Climate Change and Adaptation Strategies in Ethiopia. IFPRI Research Brief, 15, 2p.

[20] Engida, M. (1999) Annual Rainfall and Potential Evapo-Transpiration in Ethiopia. Ethiopian Journal of Natural Resources, 1, 137-154.

[21] Feyissa, G. (2006) Climate Variability and Its Role on Malaria Prevalence in Gonder Town Woreda. Unpublished Senior Essay Submitted to Department of Geography, University of Gondar, Gondar.

[22] EARO (2002) Terms of Reference for the 2002 Earo-Icra Field Study at Arsi Negele East Shoa Zone, Oromiya Region, Ethiopia.

[23] National Metrological Service Agency (NMSA) (2007) Climate Change National Adaptation Programme of Action (NAPA) of Ethiopia. NMSA, Ethiopia.

[24] Mendelsohn, R. and Dinar, A. (1999) Climate Change, Agriculture, and Developing Countries: Does Adaptation Matter? World Bank Research Observer, 14, 277-293. http://dx.doi.org/10.1093/wbro/14.2.277

[25] Oxfam (2010) The Rain Doesn't Come on Time Anymore: Poverty, Vulnerability, and Climate Variability in Ethiopia. Oxfam, Oxford.

[26] Brown, C., Meeks, R., Hunu, K. and Yu, W. (2008) Hydro-Climate Risk to Economic Growth in Sub-Sahara Africa. Climatic Change, 106, 621-647.

[27] Keely, D., Read, J. and Scavia, D. (2010) Preparing for Climate Change in the Great Lakes Region.

[28] National Metrological Service Agency (NMSA) (2001) Initial National Communication of Ethiopia to the UNFCCC. Addis Ababa.

[29] MoFED (2006) Ethiopia: Building on Progress, A Plan for Accelerated and Sustained Development to End Poverty (PASDEP) 2005/06-2009/10, September, 2006, Addis Ababa.

[30] UNFCCC (2007) Climate Change: Impacts, Vulnerabilities, and Adaptation in Developing Countries. 